\title{
Primary Closure Versus Secondary Closure after Third Molar Surgery : A Comparative Evaluation of Post - Operative Sequelae
}

\author{
Nishant Singh ${ }^{1}$, Meghna Kumar ${ }^{2}$, Shivendra Singh ${ }^{3}$, Ankit Singla ${ }^{4}$, Rahul Srivastava ${ }^{5}$ \\ ${ }^{1}$ Professor, Department of Oral and Maxillofacial Surgery, Rama Dental College, Hospital and Research Centre, Kanpur., \\ ${ }^{2}$ Post-Graduate Student, Department of Oral and Maxillofacial Surgery, Rama Dental College, Hospital and Research Centre, \\ Kanpur, ${ }^{3}$ Assistant Professor, Department of Oral and Maxillofacial Surgery, Rama Dental College, Hospital and Research \\ Centre, Kanpur, ${ }^{4}$ Post-Graduate Student, Department of Oral and Maxillofacial Surgery, Rama Dental College, Hospital and \\ Research Centre, Kanpur, ${ }^{5}$ Reader, Department of Oral Medicine and Radiology, Rama Dental College, Hospital and Research \\ Centre, Kanpur, India
}

Corresponding author: Dr Meghna Kumar (MDS), Post-Graduate Student, Department of Oral and Maxillofacial Surgery, Rama Dental College, Hospital and Research Centre, Kanpur, India

DOI: http://dx.doi.org/10.21276/ijcmsr.2020.5.1.12

(c) BY-NC-ND

How to cite this article: Nishant Singh, Meghna Kumar, Shivendra Singh, Ankit Singla, Rahul Srivastava. Primary closure versus secondary closure after third molar surgery : a comparative evaluation of post - operative sequelae. International Journal of Contemporary Medicine Surgery and Radiology. 2020;5(1):A52-A55.

\section{A B S T R A C T}

Introduction: The post-operative complications of third molar surgery vary significantly with variation in surgical technique. The purpose of this study was to assess the post-operative pain, swelling and trismus after removal of impacted third molar using primary versus second closure techniques.

Materials and Methods: In this study, 30 patients (19 males and 11 females) within the age range of 18 - 35 years requiring surgical removal of impacted mandibular third molar teeth under local anesthesia were included. Patients were divided randomly into two equal groups: Group 1 - 15 patients who underwent primary closure in which the flap was repositioned and sutured in an interrupted pattern and Group 2 - 15 patients who underwent secondary closure in whom a wedge of mucosa, width 5 - $6 \mathrm{~mm}$ was removed distal to second molar and the flap was repositioned and sutured. Parameters assessed in the study were pain, swelling and trismus.

Results: A significant difference was observed in swelling, pain and trismus at $1 \%$ level of significance. i.e. $p<0.001$ with more pain, swelling and trismus in Group 1 using the two-way ANOVA.

Conclusion: The result of our study suggests that secondary healing after surgical removal of impacted mandibular third molars may have considerable advantages over primary healing in terms of post-surgical quality of life, however multicentre studies are required to be conducted with a larger study sample.

Keywords: Impaction, Modified Ward's Incision, Primary Healing, Secondary Healing, Third Molar Surgery, Ward's Incision

\section{INTRODUCTION}

Impaction is described as the cessation of tooth eruption which occurs due to a clinically or radiographically detectable hard or soft tissue barrier in its path of eruption or by an ectopic position ${ }^{1}$ The causes of mandibular third molar impaction include both local and systemic factors. ${ }^{2}$

The sequelae of third molar impaction surgery include postoperative pain, swelling and trismus. The severity of these symptoms is dependent on multiple factors such as the operative time, the difficulty of the procedure, the extent of the ostectomy, the oral hygiene of the patient and the competence of the surgeon. ${ }^{3,4,5}$ Different authors have described multiple methods of flap raising to minimize periodontal damage to second molars. There is evidence in the literature to prove that the larger the mucoperiosteal flap, the more delayed will be the healing. ${ }^{6,7}$ There is some controversy over whether the wound should be allowed to heal by primary or secondary intention. ${ }^{8,9}$

A flap repositioning technique introduced by Rehrmann in 1936 proposed secure healing by first intention after the extraction of lower third molars. ${ }^{10}$ It was found that this technique provides adequate wound healing and avoids contamination from the oral cavity. Recently, however, authors have suggested that secondary closure of the wound aids drainage of fluid from the socket - thereby reducing the postoperative pain and the swelling. ${ }^{11}$ Previous studies recommended leaving surgical drains in the region of the wound, after reporting a better postoperative course in such patients as compared with patients who underwent primary closure. $^{12,13}$ Waite and Cherala reported excellent results following 1280 trans-alveolar extractions of mandibular third molars where they raised a small, conservative flap and repositioned it without suturing. 
The aim of this study was to compare the effect of secondary closure of the surgical wound after removal of the impacted mandibular third molar on postoperative pain, swelling and trismus to primary closure.

\section{MATERIAL AND METHODS}

A total of 30 patients, fulfilling inclusion criteria and willing for impacted lower third molar extraction, were randomly selected from the Department of Oral and Maxillofacial Surgery, Rama Dental College, Hospital and Research Centre. Ethical committee clearance was obtained along with informed consent from each patient.

These patients were randomly divided into two groups of 15 patients each:

Group-1 :15 patients in which primary closure was done after surgical extraction.

Group-2 :15 patients in which secondary closure was done after surgical extraction.

\section{Inclusion criteria}

- Patients with an indication for extraction of impacted lower third molars.

- Patients with ASA (American Society of Anaesthesiologists) physical status of I.

- Patients between the age of 18-35 years.

\section{Exclusion criteria}

- Patients with systemic diseases that can interfere with surgical therapy.

- Patients not willing to be included in the study.

- Patient with deleterious habits like smoking, tobacco, and betel nut chewing.

\section{Assessment}

Post-operative pain was scored by means of a 10 point visual analog scale (VAS) from zero (no pain) to 10 (worst pain imaginable) on the $1^{\text {st }}, 3^{\text {rd }}$ and $7^{\text {th }}$ post-operative days.

Post-operative swelling was assessed subjectively on the $1^{\text {st }}, 3^{\text {rd }}$ and $7^{\text {th }}$ post-operative days, based on a 5 -point scale (Table 1).

The swelling was assessed by both the patient and the investigator. To objectively measure swelling, two distances were recorded: (a) from a point located at mandibular angle level to the interincisal point, referred to as the angle interincisal point distance; and (b) from the tragus to the interincisal point, referred to as the tragus - interincisal point distance. Both distances were measured before the procedure and repeated three and seven days after extraction, using a non-extensible measuring tape.

Post-operative trismus was assessed by comparing the preoperative and post-operative mouth opening using a metallic scale on the day of the procedure, the $1^{\text {st }}$ post-operative day, $3^{\text {rd }}$ post-operative day and the $7^{\text {th }}$ post-operative day.

\section{Surgical Technique}

Surgical removal of the impacted third molars was performed with the patient under local anesthesia using $2 \%$ lidocaine with 1:200,000 epinephrine. The inferior alveolar, lingual, and long buccal nerves were anesthetized. A mucoperiosteal incision was placed to gain access to the third molar. A fullthickness flap was reflected. Osteotomy was performed with a straight fissure bur (no. 702), and tooth sectioning was done when necessary under constant irrigation with sterile isotonic saline. The bony margins of the sockets were filed and smoothened, and the gingival margins were freshened after removal of the teeth and irrigated with saline.

The primary closure of the socket was performed by placing 2 sutures on the distal arm of the incision and 1 on the mesial arm of the incision (Image 1). Secondary closure of the socket was performed by removing a wedge of mucosa distal to the second molar and by placing 1 suture on the mesial arm of the incision and another suture on the distal arm of the incision (Image 2). The sockets were secured using 3-0 silk sutures. Postoperative prescriptions of Amoxicillin + Potassium Clavulanate (625mg) TID, Metronidazole (400mg) TID, Aceclofenac + Serratiopeptidase + Paracetamol $(100 \mathrm{mg}+15 \mathrm{mg}+325 \mathrm{mg}) \mathrm{BD}$, and Pantoprazole (40mg) OD for 5 days respectively, were given to all patients.

\section{STATISTICAL ANALYSIS}

Two-way analysis of variance (ANOVA) analysis was performed to determine the significance of the differences between the parameters recorded for both groups.

\section{RESULTS}

30 patients having impacted third molars who were medically fit and willing to come for postoperative follow-ups were chosen randomly and divided into two groups where different closure was done. Group-1 consists of 15 patients with mean age of 29.3. Group-2 consists of 15 patients with mean age 27.3. A significant difference was observed in swelling, pain and trismus at $1 \%$ level of significance. i.e. $P<0.001$.

Pain : Results for the pain on the $1^{\text {st }}$ and $3^{\text {rd }}$ postoperative days showed peak level of pain in both groups with more pain in Group-1 as compared to Group-2. On day 7 the pain perceived was minimal in both the groups and the difference was statistically significant (Graph 1).

Swelling : There was a statistically significant difference in swelling between the two groups. Group-1 showed more swelling as compared to Group-2 throughout the week. The swelling reached its peak level on the $1^{\text {st }}$ and $2^{\text {nd }}$ postoperative days and then decreased gradually by 7 th day

\begin{tabular}{|l|l|}
\hline Score & Swelling \\
\hline 1 & The patient does not detect the slightest swelling \\
\hline 2 & The patient detects slight swelling but it is not very noticeable \\
\hline 3 & The swelling is noticeable but does not interfere with normal mastication and swallowing \\
\hline 4 & The swelling is evident and hinders normal mastication \\
\hline 5 & The swelling is very evident and there is reduced mouth opening \\
\hline \multicolumn{2}{|c|}{ Table1: Five point scale to assess post-operative swelling } \\
\hline
\end{tabular}



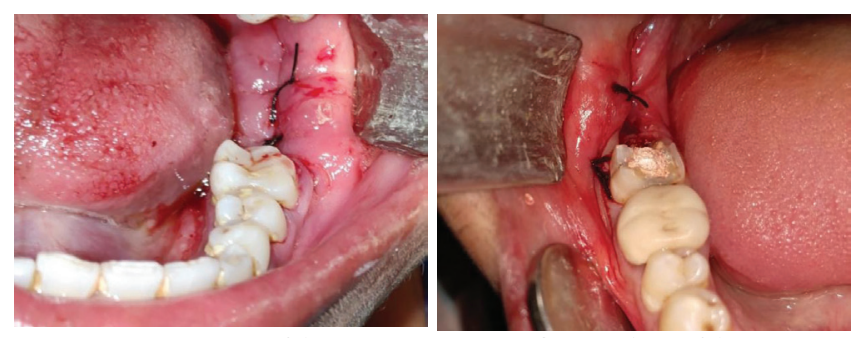

Image-1: Primary Closure; Image-2: Secondary Closure

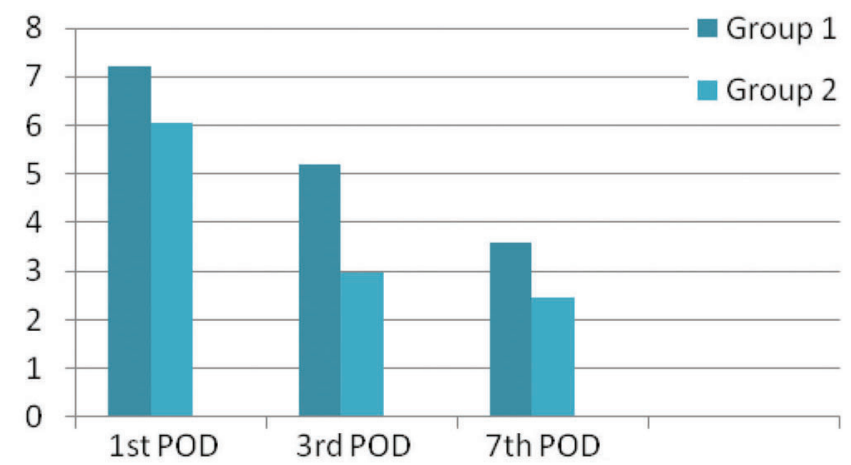

Graph-1: Comparison of post-operative pain

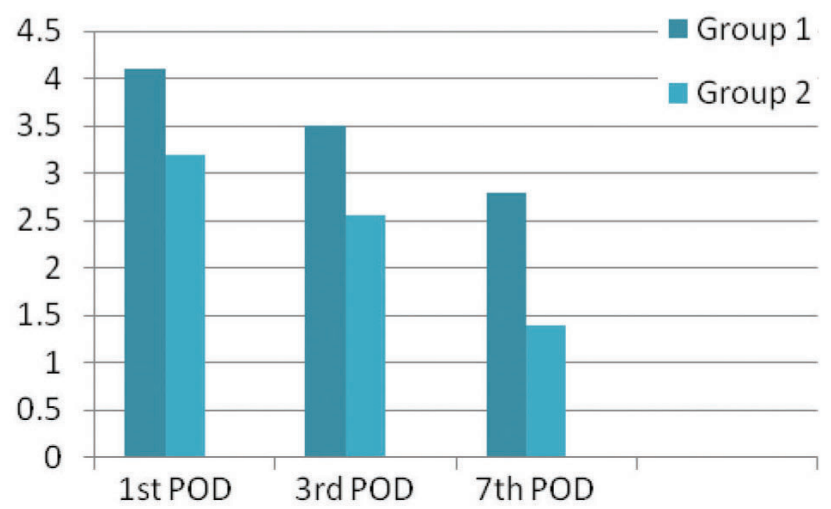

Graph-2: Comparison of post- operative swelling

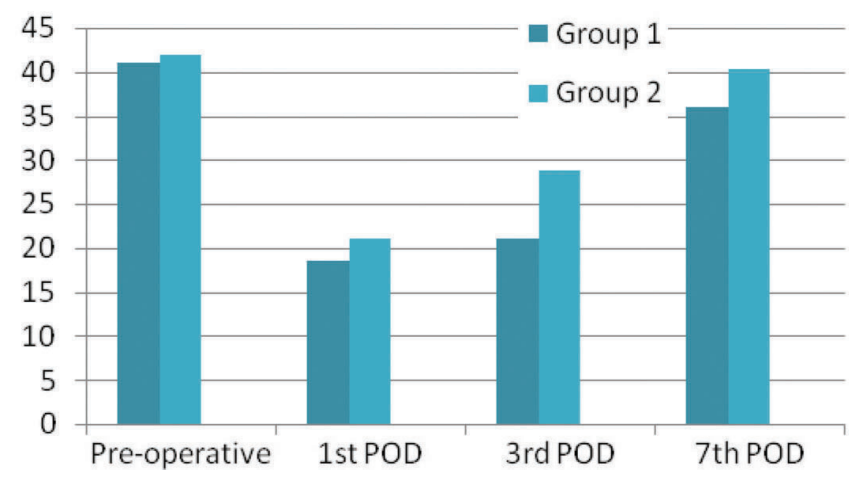

Graph-3: Comparison of Average Mouth Opening (mm)

(Graph 2).

Trismus: There was a significant difference in inter-incisal distance as measured by a metallic scale between the two groups at all times with a reduced average mouth opening in Group-1 (Graph 3).

\section{DISCUSSION}

Surgical extraction of impacted third molars is one of the most frequently performed procedures in oral and maxillofacial surgery and can lead to immediate and postoperative discomfort. ${ }^{15}$ This postoperative discomfort might be related to the surgical technique and the suturing procedure. ${ }^{16}$ The severity of pain and extent of swelling are the chief indicators of a patient's comfort during the postoperative period after transalveolar third molar removal. ${ }^{17}$ The findings of this study indicate that secondary closure significantly improves the post-operative healing following third molar surgery. However, the findings of this study are limited to only 15 patients operated using each technique.

Factors affecting pain and swelling include flap design, operative trauma, individual response to the surgical trauma and type of wound healing. ${ }^{18}$ The collection of inflammatory fluids within tissue leads to diffuse swelling in the surgical site. This pressure effect within the tissue spaces causes the post-operative complications most commonly seen after third molar removal including pain, swelling, trismus and infection (alveolar osteitis). Literature shows the use of healing by both primary and secondary intention after third molar removal. ${ }^{19}$

In the present study, we found that secondary closure was more comfortable for the patients because of less postoperative swelling, pain, and trismus. Pain was measured with visual analog scale which was a popular and routinely used pain scale. VAS is in the form of a 10 number straight line without any demarcation with the left and right extremities representing no pain and worst imaginable pain respectively. ${ }^{20}$ Swelling was assessed subjectively by the patient on a scale of 1 to 5 and by the surgeon by measuring distances from outer canthus of the eye - angle of mandible and tragus of the ear - commissure of the mouth with flexible tape preoperatively and postoperatively. We used this method of measuring swelling as it is readily available and economical which needs less equipment. Mouth opening was measured with a metallic ruler.

Dubois et al. reported that following the surgical removal of both lower molar, pain and swelling were significantly greater when the surgical wound healed by first intention. ${ }^{21}$ These findings coincide with the findings of this study. Likewise, Holland and Hindle reported more pain and swelling in those cases where primary closure was carried out. ${ }^{22}$

In contrast, Suddhasthira et al.reported no differences according to the type of wound healing involved. ${ }^{23}$ Brabander and Cattaneo observed no statistically significant differences in pain, swelling and trismus between two groups of patients who underwent primary flap closure using the conventional technique and those who underwent simple wound closure with healing by second intention. ${ }^{24}$ Regardless, all data points to a better post-operative course in patients who underwent secondary wound closure. In our case series we recorded greater trismus with primary closure.

Some authors suggested primary closure of the flap, but keeping a drain in place during 72 hours. ${ }^{25}$ While this technique has no impact upon post-operative pain, it has been proven to reduce post-operative swelling. On the contrary, Saglam recorded lesser pain, swelling and trismus in patients who underwent primary closure without placement of drain as compared to the patients who underwent pimary closure with placement of drain. ${ }^{26}$ 


\section{CONCLUSION}

The result of this study suggests that secondary healing after surgical removal of impacted mandibular third molars may have considerable advantages over primary healing in terms of postsurgical quality of life, however multicentre studies are required to be conducted with a larger study sample size.

\section{REFERENCES}

1. Anderson JO. Text Book and Color Atlas of Tooth Impaction. Copenhagen: Elsevier Science Health Science Division; 1997.

2. Lopes V, Mumenya R, Harris C. Third molar surgery: An audit of the indications for surgery, post-operative complaints and patient satisfaction. $\mathrm{Br} \mathrm{J}$ Oral MaxillofacSurg 1995;33(3):33-55.

3. Garcia Garcia A, GudeSampedro F, Gandara Rey J, GallasTorreira M. Trismus and pain after removal of impacted lower third molars. J Oral Maxillofac Surg. 1997;55(1):1223-6.

4. Capuzzi P, Montebugnoli L, Vaccaro MA. Extraction of impacted third molars. A longitudinal prospective study on factors that affect postoperative recovery. Oral Surg Oral Med Oral Pathol. 1994 ;77(5):341-3.

5. Peñarrocha M, Sanchis JM, Sáez U, Gay C, Bagán JV. Oral hygiene and postoperative pain after mandibular third molar surgery. Oral Surg Oral Med Oral Pathol Oral RadiolEndod. 2001;92(4):260-4.

6. GarcíaGarcía A, GudeSampedro F, GallasTorrella M, Gándara Vila P, Madriñán-Graña P, Gándara-Rey JM. Trismus and pain after removal of a lower third molar. Effects of raising a mucoperiosteal flap. Med Oral. 2001;6(1):391-6.

7. Clauser $\mathrm{C}$, Barone R. Effect of incision and flap reflection on postoperative pain after the removal of partially impacted mandibular third molars. Quintessence Int. 1994;25(6):845-9.

8. Dubois DD, Pizer ME, Chinnis RJ. Comparison of primary and secondary closure techniques after removal of impacted mandibular third molars. J Oral Maxillofac Surg. 1982;40(2):631-4.

9. Pasqualini D, Cocero N, Castella A, Mela L, Bracco P. Primary and secondary closure of the surgical wound after removal of impacted mandibular third molars: a comparative study. Int J OralMaxillofac Surg. 2005;34(4):52-7.

10. Rehrmann A. Einemethodezur Schlie Bungvon Kieferhöhlenperforationen. Dtsch Zahnärztl Wschr 1936:39(6);1136-40.

11. Flynn TR, Hoekstra CW, Lawrence FR. The use of drains in oral and maxillofacial surgery: a review and a new approach. J Oral MaxillofacSurg. 1983;41(5):50811.

12. De Brabander EC, Cattaneo G. The effect of surgical drain together with a secondary closure technique on postoperative trismus, swelling and pain after mandibular third molar surgery. Int J OralMaxillofac Surg. 1988;17(5):119-21.

13. Rakprasitkul S, Pairuchvej V. Mandibular third molar surgery with primary closure and tube drain. IntJ Oral Maxillofac Surg. 1997;26(1):187-90.

14. Waite PD, Cherala S. Surgical outcomes for suture-less surgery in 366 impacted third molar patients. J Oral Maxillofac Surg. 2006;64(3):669-73.

15. Goldberg Mh, Nemarich AN, Marco WP: Complications after mandibular third molar surgery: A statistical analysis of 500 consecutive procedure in private practice. J Am Dent Assoc.1985;111(2):277.

16. Pasqualini D, Cocero N, Castella A: Primary and secondary closure of the surgical wound after removal of impacted mandibular third molars: A comparative study. Int J Oral MaxillofacSurg 2003;32(3):52.

17. Winter L: Operative Oral Surgery. St. Louis, CV Mosby, 1947.

18. Grossi GB, Maiorana C, Garramone RA, Borgonovo A, Creminelli L, Santoro F. Assessing postoperative discomfort after third molar surgery: A prospective study. J Oral MaxillofacSurg 2007; 65(5):901-17.

19. Laskin DM. Text Book of Oral and Maxillofacial Surgery. Philadelphia: WB Saunders; 2013.

20. Huskisson EC (1974) Measurement of pain. Lancet 9(2):1127-1131.

21. Dubois DD, Pizer ME, Chinnis RJ. Comparison of primary and secondary closure techniques after removal of impacted mandibular third molars. J Oral Maxillofac Surg. 1982;40(3):631-4.

22. Holland CS, Hindle MO. The influence of closure or dressing of third molar sockets on post-operative swelling and pain. Br J OralMaxillofac Surg. 1984;22(6):65-71.

23. Suddhasthira T, Chaiwat S, Sattapongsda P. The comparison study of primary and secondary closure technique after removal of impacted mandibular third molars. Thai J Oral MaxillofacSurg 1991:5(4);67-73.

24. De Brabander EC, Cattaneo G. The effect of surgical drain together with a secondary closure technique on postoperative trismus, swelling and pain after mandibular third molar surgery. IntJ Oral Maxillofac Surg. 1988;17(3):119-21.

25. Rakprasitkul S, Pairuchvej V. Mandibular third molar surgery with primary closure and tube drain. IntJ Oral Maxillofac Surg. 1997;26(1):187-90.

26. Sağlam AA. Effects of tube drain with primary closure technique on postoperative trismus and swelling after removal of fully impacted mandibular third molars. Quintessence Int. 2003;34(6):143-7.

Source of Support: Nil; Conflict of Interest: None

Submitted: 02-12-2019; Accepted: 30-12-2019; Published online: 28-01-2020 